\title{
Hemolytic Activity and Siderophore Production in Different Aeromonas Species Isolated from Fish
}

\author{
JESÚS A. SANTOS, * CÉSAR J. GONZÁLEZ, ANDRÉS OTERO, AND MARÍA-LUISA GARCÍA-LÓPEZ \\ Department of Food Hygiene and Food Technology, Veterinary Faculty, University of León, E-24071 León, Spain
}

Received 3 June 1999/Accepted 23 September 1999

\begin{abstract}
The hemolytic activity and siderophore production of several strains of motile aeromonads were determined. The hemolytic activity of Aeromonas caviae and Aeromonas eucrenophila was enhanced after trypsinization of the samples. The enhancement of hemolysis was observed in strains that carried an aerolysin-like gene, detected by a PCR procedure. Siderophore production was demonstrated in all but one strain of Aeromonas jandaei. No apparent relationship was observed between the presence of plasmid DNA and hemolysis or siderophore production.
\end{abstract}

Members of the genus Aeromonas have long been considered to be human pathogens. They are implicated in a number of diarrheal and extraintestinal infections, including septicemia, wound infections, burn-associated sepsis, and respiratory tract infections $(10,11)$. However, the ultimate mechanisms of pathogenicity are not clearly understood, and several virulence factors have been proposed. Of these factors, hemolytic molecules seem to be related to enterotoxigenicity. Aerolysin (8) is the best-studied hemolysin, but Aeromonas strains can produce more than one hemolytic toxin with virulence properties (4, 22). In addition, production of siderophores has been reported for different species of Aeromonas $(1,23)$ and might be related to the virulence properties.

Of the 14 species of Aeromonas currently described, only five (A. hydrophila, A. veronii, $A$. caviae, $A$. jandaei, and $A$. schubertii) are recognized as human pathogens, but other species, like $A$. trota and $A$. eucrenophila, caused fluid accumulation in the rabbit ileal loop test after serial passages, indicating a pathogenic potential $(19,20)$, and it has been demonstrated that at least one strain of $A$. trota produces aerolysin (12).

For the present article, we investigated the hemolytic activity of strains of different species of Aeromonas isolated from freshwater fishes and the presence in them of the aerolysin gene (by PCR), as well as the production of siderophores.

Bacterial strains. Three strains of Aeromonas caviae (AC 15, AC 16, and AC 17), two of A. eucrenophila (AE 1 and AE 2), one of $A$. jandaei (AJ 1), and one of $A$. hydrophila (AH 154) were used throughout this work. The strains were isolated from samples of freshwater fish (pike, [Esox lucius], brown trout [Salmo trutta], and rainbow trout [Oncorhyncus mykiss]) and identified to the species level by biochemical methods (5). Working cultures of the microorganisms were kept on Trypticase soy agar (Oxoid) slants at room temperature and routinely cultivated in Trypticase soy broth (TSB) (Oxoid) at $28^{\circ} \mathrm{C}$.

Determination of hemolytic activity. The strains were tested for beta-hemolytic activity on Columbia agar base (Oxoid) supplemented with either 5\% rabbit erythrocytes or 5\% sheep erythrocytes with incubation at $28^{\circ} \mathrm{C}$ for $48 \mathrm{~h}$.

All of the strains were beta-hemolytic when assayed on rabbit blood agar plates, and strains $\mathrm{AC} 17, \mathrm{AE} \mathrm{1,} \mathrm{AE} \mathrm{2,} \mathrm{and} \mathrm{AH}$

\footnotetext{
* Corresponding author. Mailing address: Departamento de Higiene y Tecnología de los Alimentos, Facultad de Veterinaria, Universidad de León, E-24071 León, Spain. Phone: 34/987/291286. Fax: 34/987/291284. E-mail: dhtjsb@unileon.es.
}

154 were also beta-hemolytic on sheep blood agar plates. However, strains AC 15 (A. caviae) and AJ 1 (A. jandaei) were nonhemolytic, and strain AC 16 (A. caviae) was alpha-hemolytic on sheep blood agar plates.

For quantification of hemolysin, bacteria were cultured in TSB at $28^{\circ} \mathrm{C}$ for $18 \mathrm{~h}$, cells were pelleted by centrifugation at $10,000 \times g$ for $10 \mathrm{~min}$, and $500 \mu \mathrm{l}$ of the supernatant (filtered through $0.22-\mu \mathrm{m}$-pore-diameter filters) was added to $1 \mathrm{ml}$ of a $1 \%$ suspension of washed sheep or rabbit erythrocytes in phosphate-buffered saline (PBS; Oxoid). For activation of hemolysin precursor, the supernatants were treated with $50 \mu \mathrm{g}$ of trypsin for $15 \mathrm{~min}$ at $37^{\circ} \mathrm{C}$ before adding the erythrocyte suspension. Both nonactivated and activated reaction mixtures were incubated at $37^{\circ} \mathrm{C}$ for $60 \mathrm{~min}$ and briefly centrifuged to remove unlysed erythrocytes, and $A_{545}$ was measured to determine erythrocyte lysis. Blanks were prepared by mixing the erythrocyte suspension with sterile TSB (treated similarly to the samples), and the absorbance corresponding to $100 \%$ of hemolysis was determined by adding a small amount of sodium dodecyl sulfate to blank tubes.

The quantification of the extracellular hemolytic activity (Fig. 1) indicated that rabbit erythrocytes are more sensitive to the action of the hemolysin(s). Apart from the strain of $A$. hydrophila (AH 154), none of the strains showed an important extracellular hemolytic activity towards sheep erythrocytes, but treatment of the supernatants with trypsin resulted in significant increments of this activity in two strains of $A$. caviae (AC 15 and $\mathrm{AC} 16)$ and in both $A$. eucrenophila strains, being particularly important in AE 1 (Fig. 1A).

The extracellular activity against rabbit erythrocytes was stronger, and again, trypsin activation significantly increased the activity of strains AC 17 and AJ 1 (Fig. 1B).

The production of hemolytic toxins has been regarded as strong evidence of pathogenic potential in aeromonads. However, nonhemolytic aeromonads have been implicated as human pathogens (16). Regarding this, the routine use of sheep blood agar appears to be inappropriate, considering that sheep erythrocytes are less sensitive than erythrocytes from other mammals $(3,13)$. In our study, we observed stronger activity against rabbit blood, both on agar plates and in quantification assays.

Production of hemolysin as a precursor activatable by trypsin has been reported in several strains of Aeromonas $(8,13)$. In our case, trypsinization enhanced hemolytic activity in some of the strains tested (even though all of the strains were highly 
A

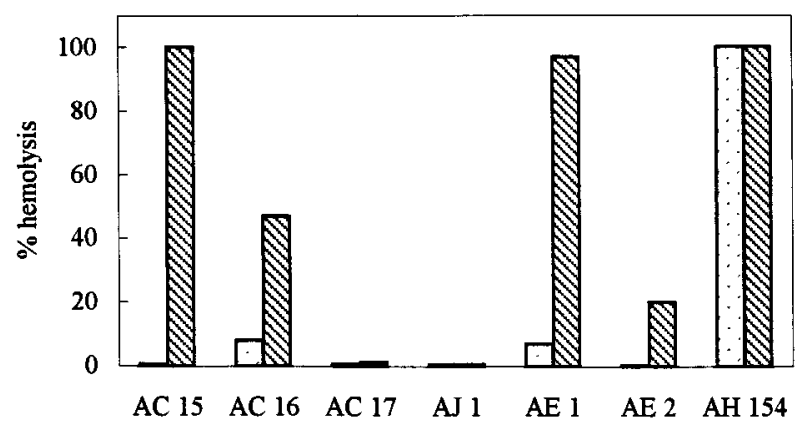

B

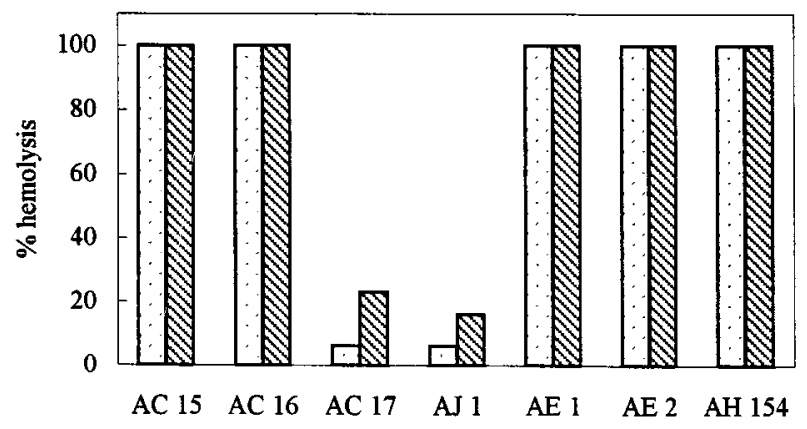

FIG. 1. Extracellular hemolytic activity of the strains of Aeromonas towards sheep (A) and rabbit (B) erythrocytes. treated samples.

proteolytic) (5), especially when less-sensitive sheep erythrocytes were used. The hemolytic activity present before trypsinization in some strains might be due to hemolysin(s) other than aerolysin. In a recent report, Wong et al. (22) demonstrated the presence of two unrelated hemolytic genes in one strain of $A$. hydrophila, both involved in virulence, but not the only genes responsible for pathogenesis.

PCR detection of aerolysin genes. DNA was isolated from the strains of Aeromonas by a common procedure (14). The published sequences of aerolysin-like genes of several Aeromonas species $(7-9,12,21)$ were screened for conserved regions, and a pair of oligonucleotide primers were synthesized. A forward primer, 5'-GC(A/T) GA(A/G) CCC (A/G)TC TAT $\mathrm{CC}(\mathrm{A} / \mathrm{T}) \mathrm{G}$ (positions 69 to 87 of the aerolysin gene [8]), was designed to target a conserved region in all of the available aerolysin sequences. The reverse primer 5'-TTT CTC CGG TAA CAG GAT TG (positions 321 to 302) was the Aero1b primer described by Pollard et al. (17).

PCR was performed on a Mastercycler Personal apparatus (Eppendorf). Initial denaturation was done at $94^{\circ} \mathrm{C}$ for $3 \mathrm{~min}$ followed by 30 cycles with denaturation at $92^{\circ} \mathrm{C}$ for $30 \mathrm{~s}$, annealing at $55^{\circ} \mathrm{C}$ for $30 \mathrm{~s}$, and extension at $72^{\circ} \mathrm{C}$ for $1 \mathrm{~min}$. A final extension step was done at $72^{\circ} \mathrm{C}$ for $1.5 \mathrm{~min}$. Aliquots from each reaction were analyzed by $1 \%$ agarose gel electrophoresis and viewed, after ethidium bromide staining, under UV light.

An amplification product of the expected size (252 bp) was observed with DNA template from strains AC 15, AC 16, AE 1, and AH 154 (Fig. 2). The amplification of the aerolysin gene was observed in strains that also showed enhancement of the

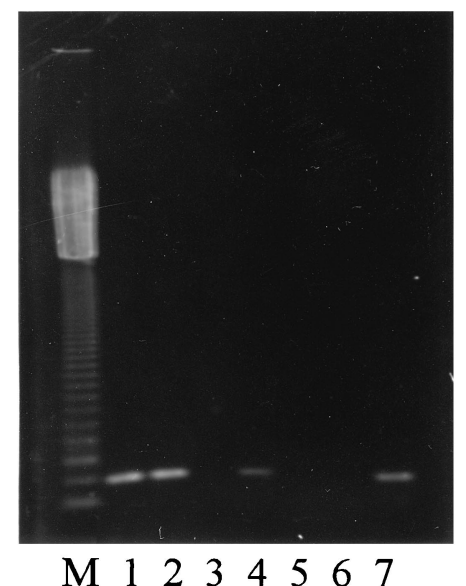

FIG. 2. Detection of the aerolysin gene by PCR in different species of Aeromonas. Lanes: M, 123-bp ladder; 1, AC 15; 2, AC 16; 3, AC 17; 4, AE 1; 5, AE 2; 6, AJ 1; 7, AH 154.

hemolytic activity by trypsinization, suggesting that some $A$. caviae and $A$. eucrenophila strains can produce an aerolysinlike gene activable under certain conditions.

Siderophore detection. The chrome azurol S siderophore detection agar (CAS agar) (18), prepared as described by Barghouthi et al. (1), was used to detect siderophore production. Single colonies of each isolate were transferred to this medium, and the plates were incubated at $30^{\circ} \mathrm{C}$ for $48 \mathrm{~h}$. The presence of an orange halo around the colonies was recorded as positive for siderophore production. Production of siderophore was detected in all but one isolate. Only one $A$. jandaei strain (AJ 1) showed no orange halo on CAS agar plates.

The production of siderophore for the isolates of Aeromonas is not remarkable, because it is a well-documented trait for this genus. More interesting is the lack of siderophore activity by a strain of $A$. jandaei, a species previously reported as siderophore producing (23). Naidu and Yadav (15) found that environmental isolates of $A$. hydrophila were less efficient than clinical strains for production of siderophores.

Plasmid analysis and curing. The strains of Aeromonas were cultured in TSB at $28^{\circ} \mathrm{C}$ for 14 to $16 \mathrm{~h}$, and plasmid DNA was isolated by the procedure of Birnboim and Doly (2). Plasmids were separated by electrophoresis in $0.8 \%$ agarose gels, stained with ethidium bromide, and visualized under UV light.

Two strains of $A$. caviae (AC 15 and AC 16) carried several plasmids, whereas no plasmid DNA was isolated from the remaining strains of Aeromonas under the conditions used in this study. The strains AC 15 and AC 16 were selected for plasmid curing experiments. The strains were cultured in TSB with ethidium bromide (10 to $300 \mu \mathrm{g} / \mathrm{ml}$ ) at $28^{\circ} \mathrm{C}$ for $48 \mathrm{~h}$, and the cultures were diluted and plated onto Trypticase soy agar. Some colonies were picked from the plates, and plasmid DNA was isolated and analyzed as described above. Hemolytic activity and siderophore production of cured strains were tested in agar plates as described above. No phenotypic changes in hemolytic activity or siderophore production were observed in the cured strains.

Hanes and Chandler (6) found that an $\mathrm{R}$ plasmid of $A$. hydrophila regulated attachment and hemolytic activities and a cured strain showed greater activities than the parental strain. In our experiments, no differences were found in hemolytic 
activities and siderophore production in $A$. caviae, indicating that these activities are not directly regulated by plasmid DNA.

In conclusion, the presence of an aerolysin-related gene was demonstrated by PCR in some strains of $A$. caviae and $A$. eucrenophila of environmental origin. The presence of this gene is related to the hemolysis of sheep erythrocytes after activation of the hemolytic protein with trypsin. We are conducting further studies to elucidate the nature of the hemolytic activities found in our strains.

This work was supported by a grant from the Spanish CICYT (Project ALI 97-0601).

\section{REFERENCES}

1. Barghouthi, S., R. Young, M. O. J. Olson, J. E. L. Arceneaux, L. W. Clem, and B. R. Byers. 1989. Amonabactin, a novel tryptophan- or phenylalaninecontaining phenolate siderophore in Aeromonas hydrophila. J. Bacteriol. 171:1811-1816.

2. Birnboim, H. C., and J. Doly. 1979. A rapid alkaline extraction procedure for screening recombinant plasmid DNA. Nucleic Acids Res. 7:1513-1523.

3. Brenden, R., and J. M. Janda. 1987. Detection, quantitation and stability of the beta hemolysin of Aeromonas spp. J. Med. Microbiol. 24:247-251.

4. Chopra, A. K., C. W. Houston, and A. Kurosky. 1991. Genetic variation in related cytolytic toxins produced by different species of Aeromonas. FEMS Microbiol. Lett. 78:231-237.

5. González-Serrano, C. J. 1996. Ph.D. thesis. Universidad de León, Leon, Spain.

6. Hanes, D. E., and D. K. F. Chandler. 1993. The role of a 40-megadaltons plasmid in the adherence and hemolytic properties of Aeromonas hydrophila. Microb. Pathog. 15:313-317.

7. Hirono, I., T. Aoki, T. Asao, and S. Kozaki. 1992. Nucleotide sequences and characterization of haemolysin genes from Aeromonas hydrophila and Aeromonas sobria. Microb. Pathog. 13:433-446.

8. Howard, S. P., W. J. Garland, M. J. Green, and J. T. Buckley. 1987. Nucleotide sequence of the gene for the hole-forming toxin aerolysin of Aeromonas hydrophila. J. Bacteriol. 169:2869-2871.

9. Husslein, V., B. Huhle, T. Jarchau, R. Lurz, W. Goebel, and T. Chakraborty. 1988. Nucleotide sequence and transcriptional analysis of the aerC aerA region of Aeromonas sobria encoding aerolysin and its regulatory regions.
Mol. Microbiol. 2:507-517.

10. Janda, J. M. 1991. Recent advances in the study of the taxonomy, pathogenicity, and infectious syndromes associated with the genus Aeromonas. Clin. Microbiol. Rev. 4:397-410.

11. Janda, J. M., and S. L. Abbot. 1998. Evolving concepts regarding the genus Aeromonas: an expanding panorama of species, disease presentations, and unanswered questions. Clin. Infect. Dis. 27:332-344.

12. Khan, A. A., E. Kim, and C. E. Cerniglia. 1998. Molecular cloning, nucleotide sequence, and expression in Escherichia coli of a hemolytic toxin (aerolysin) gene from Aeromonas trota. Appl. Environ. Microbiol. 64:2473-2478.

13. Kozaki, S., T. Asao, Y. Kamata, and G. Sakaguchi. 1989. Characterization of Aeromonas sobria hemolysin by use of monoclonal antibodies against Aeromonas hydrophila hemolysins. J. Clin. Microbiol. 27:1782-1786.

14. Lawson, P., S. E. Gharbia, H. N. Shah, and D. R. Clark. 1989. Recognition of Fusobacterium nucleatum subgroups Fn-1, Fn-2 and Fn-3 by ribosomal RNA gene restriction patterns. FEMS Microbiol. Lett. 53:41-45.

15. Naidu, A. J., and M. Yadav. 1997. Influence of iron, growth temperature and plasmids on siderophore production in Aeromonas hydrophila. J. Med. Microbiol. 46:833-838.

16. Namdari, H., and E. J. Bottone. 1990. Microbiologic evidence supporting the role of Aeromonas caviae as a pediatric enteric pathogen. J. Clin. Microbiol. 28:837-840.

17. Pollard, D. R., W. M. Johnson, H. Lior, S. D. Tyler, and K. R. Rozee. 1990. Detection of the aerolysin gene in Aeromonas hydrophila by the polymerase chain reaction. J. Clin. Microbiol. 28:2477-2481.

18. Schwyn, B., and J. B. Neilands. 1987. Universal chemical assay for the detection and determination of siderophores. Anal. Biochem. 160:47-56.

19. Singh, D. V., and S. C. Sanyal. 1997. Enterotoxicity, haemolytic activity and antibiotic susceptibility of Aeromonas eucrenophila strains isolated from water and infected fish. Indian J. Exp. Biol. 35:144-147.

20. Singh, D. V., and S. C. Sanyal. 1997. Enteropathogenicity of Aeromonas jandaei and $A$. trota. FEMS Immunol. Med. Microbiol. 17:243-250.

21. Wang, G., K. D. Tyler, C. K. Munro, and W. M. Johnson. 1996. Characterization of cytotoxic, hemolytic Aeromonas caviae clinical isolates and their identification by determining presence of a unique hemolysin gene. J. Clin. Microbiol. 34:3203-3205.

22. Wong, C. Y. F., M. W. Heuzenroeder, and R. L. P. Flower. 1998. Inactivation of two haemolytic toxin genes in Aeromonas hydrophila attenuates virulence in a suckling mouse model. Microbiology 144:291-298.

23. Zywno, S. R., J. E. L. Arceneaux, M. Altwegg, and B. R. Byers. 1992. Siderophore production and DNA hybridization groups of Aeromonas spp. J. Clin. Microbiol. 30:619-622. 